\title{
O espaço liminar das listas em romances em inglês
}

\author{
Luiz Fernando Ferreira Sá*
}

\begin{abstract}
Resumo
A esperança, a imagem e a resposta utópicas discutidas por Terry Eagleton e Georg Lukács se tornam evidentes em The studhorse man de Robert Kroetsch, Waiting for the barbarians de J. M. Coetzee, The god of small things de Arundhati Roy e City of god de E. L. Doctorow na maneira que os conflitos são, se não resolvidos, pelo menos revestidos de uma aparência insólita nas coisas e objetos inventariados em listas. Proponho pensar como as listas nos referidos romances participam na ruptura da linguagem, no colapso da narrativa, no confronto de perspectivas, na fragilidade do valor e na vacuidade de sentido. Estes romances em inglês tendem a nos dar um tipo de atalho na percepção por meio do uso de listas, enumerações e inventários, os quais suspendem a linguagem, a narrativa, a subjetividade, o valor e o sentido, em sua confusa voracidade e infinidade.
\end{abstract}

Palavras chave: Romance inglês. Listas. Ruptura narrativa.

\section{The Liminal Space of Lists in Novels in English}

\begin{abstract}
The utopian hope, image, and response discussed by Terry Eagleton and Georg Lukács are made evident in The Studhorse Man by the Robert Kroetsch, Waiting for the Barbarians by J. M. Coetzee, The God of Small Things by Arundhati Roy, and City of God by E. L. Doctorow in the way the conflicts are, if not resolved, at least given a poetic veneer in the things and objects inventoried on lists. I show how the lists in the said novels participate in the overall break-up of language, in the collapse of narrative, in the clash of subjective standpoints, in the fragility of value and in the elusiveness of meaning. These novels in English tend to give us a kind of foreshortening of perception through the use of lists, enumerations, and inventories, which suspend language, narrative, subjectivity, value, and meaning in their dizzying voraciousness and infinity.
\end{abstract}

Keywords: English novel. Lists. Narrative rupture. 
O romance é discutivelmente a forma mais importante na arte ocidental, um certo non plus ultra, pois ele pretende representar a totalidade da vida ao mesmo tempo em que exerce uma força emblemática contra o pensamento sistemático de vários saberes. De maneira geral, o romance se tornou o livro moderno da vida: uma das melhores representações de nossa experiência do mundo. Esse gênero literário narra uma época e uma sociedade em que as experiências individuais não convergem, mas proliferam, em que o mundo comum se fragmentou em uma pluralidade de mundos pequenos e locais, cada um absoluto em sua particularidade. Narrativamente, então, o romance produz uma série acrecionária de fontes, de testemunho visual e não visual, que afeta a retórica de validação junto às realidades possíveis, mas também projeta a aura de seu alcance ubíquo e relativamente irônico, alistando coisas e objetos em sua cadeia de investimento.

Terry Eagleton, em The English novel, se pergunta por que o romance é uma forma irônica. A sua resposta: porque "ao refletir a vida diária, o romance também aponta o seu distanciamento essencial dela" (EAGLETON, 2005, p. 15). ${ }^{2}$ Ele prossegue dizendo que, embora tenhamos um vislumbre de reconciliação na maioria dos romances ingleses, "mesmo que seja puramente ficcional, [esta reconciliação] representa uma espécie de esperança utópica” (2005, p. 15). ${ }^{3} \mathrm{O}$ crítico conclui suas ideias sobre o caráter reconciliatório do romance inglês: "o romance é uma imagem utópica - não no que ele representa, que pode ser bem perturbador, mas no próprio ato de representação -, um ato que, em sua feição mais efetiva, forma o mundo com sentido, sem prejuízo à sua realidade. Neste caso, o ato de narrar é um ato moral" (EAGLETON, 2005, p. 16). ${ }^{4}$

Ainda de acordo com Eagleton, quando o romance é mais verdadeiramente realista e menos essencialmente realístico (partidário do realismo), “o que ele reflete de modo mais importante não é o mundo, mas a maneira pela qual o mundo passa a existir apenas sob a nossa perspectiva no momento em que conferimos forma e valor a ele" (EAGLETON, 2005, p. 17). ${ }^{5}$ Destarte, Eagleton declara, seguindo o pensamento de Georg Lukács em Theory of the novel, que "o romance é o produto de um mundo alienado. Contudo, ele é também uma resposta utópica a isto" (EAGLETON, 2005, p. 18). ${ }^{6}$ Apesar de serem críticos literários se utilizando de marcos teóricos sutilmente distintos entre si, Eagleton afirma, com Lukács, que o romance "é uma forma de arte que não pode mais moldar as contradições que o afligem em um todo coerente" (EAGLETON, 2005, p.19). ${ }^{7}$ A partir de tal afirmação, minha leitura de The studhorse man de Robert Kroetsch, Waiting for the barbarians de J. M. Coetzee, The god of small things de Arundhati Roy e City of god de E. L. Doctorow discute o espaço liminar das listas ${ }^{8}$ como o local de apresentação e negociação destas contradições e conflitos, bem como estas contradições irrompem em aparições insólitas que se infiltram na própria forma do romance. De volta a Eagleton, os conflitos "se refletem na ruptura da linguagem, ${ }^{9}$ no colapso da narrativa, ${ }^{10}$ na não fiabilidade dos relatos, no confronto de pontos de vista subjetivos, na fragilidade

\footnotetext{
2 Todas as traduções são minhas. No original: In reflecting everyday life, it also signals its essential distance from it. 3 No original: even if it is purely fictional, [this reconciliation] represents a kind of utopian hope.

4 No original: The novel is a utopian image - not in what it represents, which can be gruesome enough, but in the very act of representation — an act which at its most effective shapes the world into meaning with no detriment to its reality. In this sense, to narrate is itself a moral act.

5 No original: What it reflects most importantly is not the world, but the way in which the world comes into being only by our bestowing form and value upon it.

6 No original: The novel is the product of an alienated world. Yet it is also a utopian response to it.

7 No original: Is an art form which can no longer shape the contradictions which plague it into a coherent whole.

8 Veja-se Eco (2009) sobre a tipologia das listas e sobre os excessos enumerativos coerentes e incoerentes.

9 A ruptura da linguagem, de acordo com Eagleton, se dá em termos de um rompimento, de uma cisão, que divide a linguagem em unidades concorrentes e conflitantes menores.

10 Uma narrativa se desenvolve ao longo do tempo e nos leva a um ponto final lógico e conclusivo; Eagleton afirma que o nosso senso convencional de continuidade, de narrativa linear, vem sendo desorientado desde o início do século XX, pois não há mais compatibilidade entre o arco narrativo tradicional e o mundo contemporâneo.
} 
do valor, na vacuidade de um sentido geral" (EAGLETON, 2005, p. 19). ${ }^{11}$

É meu argumento, então, que a esperança, a imagem e a resposta utópicas discutidas por Eagleton e Lukács se tornam evidentes nos romances elencados na maneira que os conflitos são, se não resolvidos, pelo menos revestidos de uma aparência insólita nas coisas e objetos inventariados em listas. Logo, os romances em questão tendem a nos dar um tipo de atalho na percepção por meio do uso de listas, enumerações e inventários, os quais suspendem a linguagem, a narrativa, a subjetividade, o valor e o sentido, em sua confusa voracidade e infinidade. Devo acrescentar que Eagleton, no decorrer de sua análise, não se utiliza de acumulação vocabular para demarcar as singularidades desse gênero literário e, já adianto, chega a uma conclusão diferente da minha: o romance tende a nos dar, ao invés de conflitos em relação à esperança, imagem e resposta utópicas, "um tipo de significante vazio de uma totalidade que não é mais possível” (EAGLETON, 2005, p. 19). ${ }^{12}$ Tal constatação está longe de ter se exaurido e continua a render frutos para a nossa mais exigente leitura de romances mais recentes. ${ }^{13}$

Um significante vazio de uma totalidade fora do eixo não é mais possível de ser pensado em relação a romances em inglês dos anos 70 ao início do século XXI, porque o nosso mundo contemporâneo não está simplesmente fora do eixo, mas, em última análise, se encontra num mo(vi)mento de disjunção. Então, sugiro que é ao recurso de uma arte disjuntiva (ars disjunctoria) que os romancistas retornaram. Esta ars disjunctoria se materializa como a esperança, a imagem e a resposta utópica com relação a desejos que permitem que as partes em deriva das narrativas lançadas vagueiem, se misturem e se suplementem. As partes em deriva se suplementam nas muitas listas ensaiadas nos romances aqui trabalhados e as listas se tornam, elas mesmas, um espaço de liminaridade, de utopia ou um espaço onde o insólito não mais é um outro, o desconhecido ou assustador, o monstruoso ou maravilhoso, para tornar-se um real, por assim dizer, mais-do-que real. O espaço utópico-insólito criado a partir das listas nestes romances tem relação com uma possível falha, fissura do e no realismo formal, e se agrava com a conclusão, de Eagleton e Lukács, de que o ato de narrar é, ele mesmo, um ato moral.

Narrado "na moral", a linha básica do romance de Kroetsch, The studhorse man (1970), se enreda na história de Demeter Proudfoot e nos problemas relativos a todo escritor-biógrafo, como também na vida de Hazard Lepage, um homem que possui um garanhão, Poseidon, à procura de uma égua para procriação. Ao atravessar uma das províncias/planícies canadenses (Alberta), Hazard vivencia aventuras insólitas que o desviam de seu objetivo: cruzar o seu garanhão. Um final feliz é brevemente cotejado, porém Poseidon mata seu mestre e Eugene Utter, o sócio de Hazard, toma conta do negócio e se casa com a antiga noiva de Lepage. Não só há ironia na forma como o novo casal prospera na procriação de cavalos por meio da urina de éguas prenhas, das quais os cientistas extraem estrogênio para usar na produção de pílulas anticoncepcionais, mas também no desfecho do romance, um verdadeiro espetáculo de celebração da morte e da vida, da escrita simultânea de si e do outro, das formas do mundo e de um real mais-do-que a vida.

Robert Kroetsch, que enfatiza a descontinuidade e um método perceptual direto, vê a ficção, a linguagem e a (des)ordem como um processo no qual o leitor trabalha com o escritor em um mundo incerto e alternante, e não como um produto pronto e ordenado que o leitor simplesmente entende e passivamente contempla. Quais são as passagens que contemplam e removem a ordem simultaneamente? A primeira passagem, a única que vou reproduzir aqui, uma lista bela, é direcionada à biblioteca de Hazard, a maior parte de seu conhecimento adquirido:

11 No original: Reflect themselves in the break-up of language, the collapse of narrative, the unreliability of reports, the clash of subjective standpoints, the fragility of value, the elusiveness of overall meaning.

12 No original: A kind of empty signifier of a totality which is no longer possible.

13 Michael Greaney (2006) e Guido Mazzoni (2017) nos oferecem leituras sobre o romance contemporâneo que retomam Erich Auerbach, Georg Lukács, Ian Watt e dialogam com Terry Eagleton. 
Hazard carinhosamente amava ler. Sua poesia e sua filosofia eram uma coleção antiga de capa de couro chamada The General Stud Book. O inglês que construiu a mansão isolada e padeceu dentro de suas paredes trouxe o volume com ele, que só Deus sabe de onde, se era de uma casa elegante de um lorde inglês ou uma livraria poeirenta de Londres. Estes volumes eram a história de Hazard sobre o homem e sua teologia. Sentado, ele não podia deixar de confrontar o caos nas prateleiras de livros ao lado de sua mesa: uma serra e uma corda para pentear e laçar cavalos, uma colher presa a uma barra para o gotejamento de trigo envenenado nos buracos de tartarugas infecciosas, sal cristalino, raiz de uma erva, pinos de cobre espalhados, um metal preto, uma régua escolar, três ratoeiras em uma caixa de fósforos, duas limas de metal para aparar cascos, Cornucrescine (para fazer chifres crescerem), gengibre, loção para aplicar em dorso de cavalos, esta mesma loção com a marca real de Elliman, sulfato hidratado de cobre, uma mistura de vários materiais [um eletuário], uma poção venenosa de uma planta [noz vômica], sabão de sela em um vaso de cerâmica (um simples azul e branco), mosca espanhola (KROETSCH, 1970, p. 11). ${ }^{14}$

Por meio de um jogo com Jorge Luis Borges e de uma negociação com Michel Foucault (1970), mantém-se um senso de interação entre o real e o mais-do-que a vida, particularmente na listagem da mosca espanhola, na livraria poeirenta de Londres e na casa elegante de um lorde inglês que se volta aos elementos rurais das ratoeiras, das misturas para fazer crescer chifres e das loções para cavalos. Na base dessas atividades está o desejo de saber de onde as coisas vêm; não exatamente uma procura por origens antigas, mas, mais do que isso, um jogo irônico de suplementação de origens tanto encontradas quanto fabricadas. O que Kroetsch parece fazer, ao longo de seu romance, é jogar o campo da recusa contra o do desejo, isto é, ele exige que nós tentemos perceber momentos de realidade e pontos de uma insólita utopia - quase sempre negando que uma percepção abrangente seja possível.

A primeira lista participa na ruptura geral da linguagem, pois ela não é mais concebida tão somente como um sistema fechado, mas deve ser pensada em sua prática, atribuindo importância ao diálogo travado com o simbólico, com a divisão política dos sentidos, os quais se tornaram moventes e instáveis, como se fossem $\operatorname{tax}^{15}{ }^{15}$ de sistemas indecidíveis; no colapso da narrativa, uma vez que os fatos expostos não são apresentados seguindo determinada ordem, mas acumulados numa condensação disjuntiva e poética; no confronto de pontos de vista subjetivos, dado que os volumes da biblioteca de Hazard sobre o Homem e sua teologia não coadunam com os objetos listados; na fragilidade de valor, em razão da teologia do Homem se resumir a uma tecnologia quase vulgar na sua menção última à mosca esponhola, simplesmente morta ou conservada como um espécime raro num gabinete de curiosidades; e na vacuidade de sentido, em virtude de um senso de abertura tal que tangencia o inconcebível, que toca a superfície daquilo que escapa às operações ligadas à nomeação, que transforma de forma paradoxal o nada em pleno. Portanto, esta primeira lista é um tipo de espaço liminar, de atalho utópico, uma senda insólita desestruturadora da ordem das coisas, que se rompe frente ao conhecimento formal na rede de listas que compõe este romance.

Vale acrescentar que entendo por senda insólita, ou mesmo senda recheada de elementos insólitos, o espaço de articulação da suposta "sub-versão do real", ou seja, formar o mundo com sentido sem prejuízo à sua realidade. Em outras palavras, o espaço liminar-insólito das listas em The studhorse

14 No original: Hazard dearly loved to read. His poetry and his philosophy were a leatherbound stained ancient collection called The General Stud Book. The Englishman who built the isolated mansion and perished within its walls had brought the volume with him from God knows what elegant manor house or dusty London bookshop. Those volumes were Hazard's history of man and his theology. Sitting, he could not help but confront the chaos on the bookshelves beside the desk: currycombs, a broken hamestrap, a spoon wired to a stick for dropping poisoned wheat into the holes of offending gophers, saltpeter, gentian root, a scattering of copper rivets, black antinomy, a schoolboy's ruler, three mousetraps in a matchbox, two chisels for trimming hoofs, Cornucrescine (for making horn grow), ginger, horse liniment and liniment for his back, Elliman's Royal Embrocation, blue vitriol, an electuary, nux vomica, saddle soap in a Spode (a simple blue and white) saucer, Spanish fly.

15 Plural de taxón, unidade taxonômica. 
man não se refere a uma temática (do insólito, do utópico ou distópico), mas se apresenta no momento que não se desvenda a realidade ou o desejo, porém se cria um mundo perpassado por fantasmagorias de toda ordem, seres e coisas mais-do-que a vida, um mundo onde a realidade enche-se de júbilo ao passar por aparatos óticos que produzem distorções e verdadeiras aparências.

Se nos atermos aos aparatos óticos, desta feita de distorção da força política, é de se esperar que um romancista sul-africano seja mais direcionado a ouvir as vozes dos menos privilegiados e entrever as máscaras da civilização. De J. M. Coetzee, Waiting for the barbarians, um romance de 1980, é um texto consistentemente preocupado em pontuar os sistemas de opressão e as resistências a eles, e, muito frequentemente, a figura do Império é uma forma personalizada de tais sistemas. Um poema escrito em 1904 pelo escritor grego Constantine Cavafy dá origem ao título do romance de Coetzee e promove a base essencial de sua narrativa: para que algo como um império exista, tem de haver algo para resistir a ele - um opositor, um espelho, um outro contra o qual ele se defin(h)a. O senhor é concebido e depende da oposição a seu escravo, assim como o verso depende de sua oposição ao reverso, o dentro ao fora, o real ao supernatural (irreal ou insólito) e a civilização à barbárie.

$\mathrm{O}$ romance detalha a queda em desgraça de um magistrado nada excepcional do Império e expõe a brutalidade e a falência que acompanham os projetos coloniais e imperiais movidos pelas filosofias de poder/saber e pelos delírios que acompanham toda ilusão de se estar fazendo a coisa certa. O narrador magistrado se contrapõe a duas outras personagens: o primeiro é Coronel Joll, agente de inteligência que trabalha no palimpséstico Third Bureau. A segunda personagem é uma jovem mulher bárbara, cega e abusada pelo Coronel Joll em sua "esclarecida" coleta de informações. A esta jovem nativa, o magistrado revela o tema central do romance: o terror de uma imaginação realista. "Nada é pior do que o que nós podemos imaginar", ele sussurra em um momento íntimo e finaliza: "não faça mistério sobre isto, dor é dor" (COETZEE, 1982, p. 34). ${ }^{16}$

A primeira lista de Waiting for the barbarians, ${ }^{17}$ além de tantos outros inventários ao longo do romance, também apresenta a ruptura geral da linguagem no momento em que um problema de decisão é qualquer questão arbitrária de sim-ou-não sobre um conjunto infinito de entradas, quais sejam, a dor, a submissão, a responsabilidade, a verdade, a dúvida e seus correlatos; o colapso da narrativa se faz presente no que tange ao itinerário poético que percorre o caminho entre a dor e a dúvida, passando pela submissão, responsabilidade e verdade; o confronto de pontos de vista subjetivos emerge da pergunta retórica se a dor humana de maior extensão é a verdade ou a dúvida; a fragilidade de valor se esconde na enigmática afirmação: a verdade é dor; e a vacuidade de sentido nos toma de surpresa: seria o nada da verdade o pleno da dor ou o nada da dor o pleno da verdade? Podemos chamar a seguinte lista de uma enumeração e de um império de dor:

... o meu ouvido está ligado ao tom maior da dor humana. [...] 'Não é uma posição terrível? Imagine: ser preparado para submeter-se, submeter-se, não ter mais nada a não ser se submeter, ser quebrado, e ainda, ser pressionado a se submeter mais! E que responsabilidade para o interrogador! Como você sabe se um homem lhe falou a verdade? [...] O tom da verdade! Você consegue perceber este tom no discurso do dia-a-dia? Você consegue ouvir se eu estou falando a verdade? [...] Eu estou falando de uma situação na qual eu procuro pela verdade e, na qual eu tenho que exercer pressão para achá-la. Primeiro, eu recebo mentiras, você vê - isso é o que acontece - primeiro mentiras, depois pressão, depois mais pressão ainda, depois a quebra, depois mais pressão, depois, então, a verdade. É assim que você obtém a verdade'. A dor é a verdade; o resto todo se sujeita à dúvida (COETZEE,

16 No original: Nothing is worse than what we can imagine...don't make a mystery of it, pain is only pain.

17 De acordo com Eco (2009, p. 137), esta lista é tanto um polissíndeto (modalidade de um elenco com conjunções: “depois pressão, depois mais pressão ainda, depois a quebra, depois mais pressão, depois ... a verdade") como um tipo de acumulação ligado à anáfora (retomada da mesma palavra: submeter-se, submeter-se, se submeter, se submeter) e cujo efeito narrativo é produzir uma vertigem sonora. 
1982, p. 5). ${ }^{18}$

Devemos parar um pouco para examinar esta dúvida. Alguns podem pensar: aqui ele se refere à distopia e a um espaço distópico. Ora, não estou a discutir modos ou instâncias genéricas de utopias ou ocorrências insólitas, o que me interessa nesta passagem particular e neste artigo, de forma mais ampla, é uma espécie de "utopia formal", e eu sigo a linha de pensamento iniciado com Watt, Auerbach, Lukács e Eagleton. Em outras palavras, é precisamente esta ilusão de uma transcendência tornada acessível por meio da autocomiseração e posterior tortura, de si e do outro, por parte do magistrado-narrador, que o implica ainda mais graficamente no discurso das listas (especialmente com relação à vertigem sonora produzida) e de sua utopia formal. Essa ilusão é possível em razão do impacto do processo de tortura (a si mesmo e à mulher), seu excesso esmagador sobre a experiência "comum" em última análise aponta a indefinição ou a vacuidade de sentido. Em suma, a verdade, para ser concebível, se baseia na concepção e no exercício da dor.

É importante frisar que o espaço utópico/insólito em Waiting for the barbarians se faz aparente no momento em que não se percebe completamente a realidade ou o desejo, mas se descortina um mundo perpassado por espectros, seres e coisas mais-do-que a vida, um mundo onde a realidade enche-se de angústia e horror ao passar por aparatos óticos que produzem distorções e verdadeiras aparências. Na lista em questão, conclui-se que a verdade é dor, o resto é dúvida.

Em seguida, antes de analisar de forma sucinta uma lista de The god of small things, romance de Roy publicado em 1997, traço uma analogia entre as listas lá discutidas e o transbordamento das coisas inventariadas que perfazem um envelope de circunstâncias no romance de Henry James, The portrait of a lady: "Eu não me importo com nada em sua casa", disse Isabel. E a resposta de seu interlocutor:

Isso é muito inocente de sua parte. Quando se viveu tanto tempo quanto eu vivi, você verá que cada ser humano tem sua concha e que você deve levar a concha em consideração. Com concha, quero dizer todo o envelope de circunstâncias. Não existe tal coisa como um homem ou mulher isolado; nós somos cada um de nós feito de algum conjunto de pertences. O que devemos chamar de nosso 'eu'? Onde começa? Onde isso vai parar? Isso transborda em tudo o que nos pertence - e, em seguida, isso flui de volta. Eu sei que uma grande parte de mim está nas roupas que eu escolho para vestir. Tenho um grande respeito por coisas! O 'eu' - para outras pessoas — é a própria expressão de si mesmo; e a sua casa, seus móveis, suas vestimentas, os livros que se lê, as amizades que se mantém - estas coisas são todas expressivas (JAMES, 1986, p. 37). ${ }^{19}$

Todas estas coisas são expressivas, pois constroem uma concha e, de acordo com Eagleton e Lukács, elas tão bem moldam o mundo com significado e são concomitantemente um ato moral.

De volta ao romance de Roy, The god of small things revela uma complexa relação entre os indivíduos e as forças históricas e culturais, relação esta que dá forma aos indivíduos, ao mundo em

18 No original: My ear is even turned to the pitch of human pain. ... 'Is that not a terrible position? Imagine: to be prepared to yield, to yield, to have nothing more to yield, to be broken, yet to be pressed to yield more! And what a responsibility for the interrogator! How do you ever know when a man has told you the truth? ... The tone of truth! Can you pick up this tone in everyday speech? Can you hear whether I am telling the truth? ... I am speaking of a situation in which I am probing for the truth, in which I have to exert pressure to find it. First I get lies, you see - this is what happens - first lies, then pressure, then more lies, then more pressure, then the break, then more pressure, then the truth. That is how you get the truth'. Pain is truth; all else is subject to doubt.

19 No original: “I don't care anything about his house", said Isabel. "That's very crude of you. When you've lived as long as I you'll see that every human being has his shell and that you must take the shell into account. By the shell I mean the whole envelope of circumstances. There is no such thing as an isolated man or woman; we're each of us made of some cluster of appurtenances. What shall we call our 'self'? Where does it begin? Where does it end? It overflows into everything that belongs to us - and then it flows back again. I know a large part of me is in the clothes I choose to wear. I've a great respect for things! One's self - for other people - is one's expression of one's self; and one's house, one's furniture, one's garments, the books one reads, the company one keeps - these things are all expressive." 
que eles vivem e ao romance em si. Um Deus Grande preside aos grandes acontecimentos do mundo, o "vasto, violento, circular, enérgico, ridículo, insano, inviável tumulto público que é uma nação" (ROY, 1997, p. 19), ${ }^{20}$ enquanto um Deus Pequeno dirige as vidas individuais envoltas em tensões e conflitos de toda sorte. Uma série de espantosos contratempos e de pequenas tragédias acomete os indivíduos a quem o Deus Pequeno acolhe. Frente aos movimentos do mundo ou da nação, alguns adotarão resignação, inconsequência e indiferença e outros serão oprimidos até se esquecerem de si, do mundo em que vivem e da (falta de) moral nas narrativas que os cercam.

O Deus Pequeno definitivamente vai ao encontro do Deus Grande para presidir a seguinte lista:

Baby Kochamma adorava a casa em Ayemenem e acalentava os móveis que ela tinha herdado por sobreviver a toda a gente. Violino e estante de violino de Mammachi, os armários Ooty, as cadeiras de cerdas de plástico, as camas provenientes de Nova Deli, a penteadeira de Viena com puxadores de marfim rachados. A mesa de jantar em jacarandá que Velutha fez. ... Ainda assim, dizer que tudo começou quando Sophie Mol veio para Ayemenem é apenas uma maneira de olhar. Igualmente, seria possível argumentar que, na verdade, tudo começou há milhares de anos. Muito antes de os marxistas chegarem. Antes que os ingleses tomassem Malabar, antes da ascendência holandesa, antes de Vasco da Gama chegar, antes da conquista de Calecute por Samorim. Antes de três bispos sírios, vestidos de roxo, serem assassinados pelos Portugueses e depois encontrados flutuando no mar, com serpentes marinhas enroladas em seus peitos e ostras amarradas em suas barbas emaranhadas. Pode-se argumentar que tudo começou muito antes do cristianismo chegar de barco e se infiltrar no dia-a-dia de Kerala como chá em um saquinho de chá. Tudo realmente começou na época em que as leis do amor foram feitas. As leis que estabelecem quem deve ser amado, e como. E quanto (ROY, 1997, p. 28, 33).21

Esse inventário e essa acumulação, longe de conter e simplesmente espelhar a hierarquia da existência, desempenham um papel central em uma cultura de desorientação sistemática; apontam uma realidade diferente, já não nos remetem ao tranquilizador e lógico mundo dirigido pela ordem divina ou por um desígnio civilizatório, mas passam o olhar por sobre o aberrante e desconexo mundo de hoje: os relacionamentos estão rotos e desgastados, jardins estão em ruínas, lares estão devastados, vítimas da sujeira abjeta alimentada pela apatia e negligência.

Encontros e desencontros são claramente perceptíveis na lista acima: a ruptura geral da linguagem parece se dar no momento em que o começo de tudo se dissolve num tempo mítico onde as leis do amor teriam sido feitas e, concomitantemente, herança e sobrevivência se tornam matéria linguística por meio de objetos, móveis; o colapso da narrativa segue o rompimento anterior no sentido de estabelecer o início de tudo num ponto de fuga temporal ou numa anterioridade imaterial (outro itinerário poético que percorre o caminho entre a dor e a dúvida, mas agora passando por puxadores de marfim rachados e barbas emaranhadas à deriva); o confronto de pontos de vista subjetivos é delineado de maneira sutil, pois nos perguntamos se quando tudo começa é apenas uma maneira de olhar; a fragilidade de valor emerge por meio de justaposição: as leis que estabelecem quem deve ser amado, como e quanto, se justapõem à forma com que Baby Kochamma adorava a casa e acalentava

20 No original: vast, violent, circling, driving, ridiculous, insane, unfeasible, public turmoil of a nation.

21 No original: Baby Kochamma loved the Ayemenem house and cherished the furniture that she had inherited by outliving everybody else. Mammachi's violin and violin stand, the Ooty cupboards, the plastic basket chairs, the Delhi beds, the dressing table from Vienna with cracked ivory knobs. The rosewood dining table that Velutha made....Still to say that it all began when Sophie Mol came to Ayemenem is only one way of looking at it. Equally, it would be argued that it actually began thousands of years ago. Long before the Marxists came. Before the British took Malabar, before the Dutch Ascendency, before Vasco da Gama arrived, before the Zamorin's conquest of Calicut. Before three purple-robed Syrian Bishops murdered by the Portuguese were found floating in the sea, with coiled sea serpents riding on their chests and oysters knotted in their tangled beards. It could be argued that it began long before Christianity arrived in a boat and seeped into Kerala life like tea from a teabag.

That it really began in the days when the Love Laws were made. The laws that lay down who should be loved, and how. And how much. 
os móveis; e a vacuidade de sentido enrudece nas coisas que flutuam em amarrados e emaranhados, se tudo se infiltra e torna o mundo ao redor um espaço potencial de porosidades, como chá em um saquinho de chá, qual seria o sentido das coisas?

Tais coisas, sumariamente agrupadas de acordo com as leis que levam em conta a coerência dos itens listados, não são os acidentes externos ou saltos imponderáveis e arbitrários do inconsciente, elas, as coisas, estão, antes de tudo, despedaçadas e desligadas de seu significado mundano, de seu significado cotidiano, e mistificadas, feitas livres mais uma vez e capazes de assumir um sentido que é insólito, misterioso e irracional: o que é feito insólito é a "realidade", o fenômeno multifacetado que uma ironia transcendental destrói com o fogo. Isto, em resumo, é o que venho chamando de utopia formal e de insólito "natural".

Há muito na obra de Doctorow para incentivar a designação de naturalmente insólita ou insolitamente natural: a trama central de City of god, romance datado de 2001, diz respeito à criação e à resolução de uma série de quebra-cabeças, e o próprio Doctorow em comentários sobre sua escrita usa o enigma do quebra-cabeça como uma metáfora explicativa. Sua fidelidade a esta metáfora indica que ela funcionou para ele, mas não significa necessariamente que o uso de quebra-cabeças, listas e metáforas descreve com precisão o seu labor de escritor. Diversamente povoado e amplamente insólito, o romance de Doctorow ainda pode ser visto como um retrato primorosamente singular da imaginação peripatética de um homem e seu fluxo de consciência. Tudo que lemos em City of god, do padre episcopal em meio a uma crise de fé e de um rabino enlutado esforçando-se para redirecionar o destino de toda a tradição judaica, à angustiante narrativa de gueto de um sobrevivente do Holocausto e o luxuriante par de versos imagéticos sobre as Guerras Mundiais, presumivelmente flui de um cursor manipulado por um escritor Nova-iorquino de meia-idade chamado Everett.

Com Everett como seu protagonista, um atormentado Everyman, Doctorow oferece aos leitores uma lista, arquivo, catálogo abrangente do século XX, canalizando as vozes de Albert Einstein, Ludwig Wittgenstein e Frank Sinatra, bem como as vezes de vários seres ficcionais que ocupam tanto a narrativa principal do romance quanto as suas narrativas periféricas. Começando com o título de seu romance e suas implicações agostinianas, cada espectro do arquivo-romance de Doctorow está a serviço de questões relativas à origem da fé, ao mistério da consciência humana, e à falência da ideia que se criou de Deus. Seleciono, em meio a várias outras listas, enumerações, catálogos e arquivos estupefacientes, a seguinte passagem:

Mas eu posso parar em qualquer canto na interseção de duas ruas movimentadas, e em minha frente estão milhares de vidas se movimentando em todas as quatro direções, para os subúrbios, para o centro, leste e oeste, a pé, em bicicletas, em patins in-line, em ônibus, andadores, carros, caminhões, com o barulho do metrô retumbando sob meus pés ... e como não saber que eu sou momentaneamente parte do fenômeno mais espetacular do mundo não-natural? Há um reconhecimento de espécie que nunca vamos admitir. A sobrealma primacial. Apesar de toda a desconfiança ou indiferença com que negociamos nossos espaços públicos, contamos com as massas em torno de nós para nos delinear. A cidade pode começar a partir de um mercado, um posto de troca, a confluência das águas, mas secretamente depende da necessidade humana de caminhar entre estranhos.

E assim cada um dos transeuntes nesta esquina, cada desalinhado, acima do peso, abaixo do peso, estranho, gordo ou robusto ou claudicante ou balbuciante ou estrangeiro, ou punk de cabelo verde, ameaçador, louco, irritado, pessoa inconsolável que vejo ... é um novaiorquino, o que quer dizer tão nativo a esta diáspora como eu sou, e parte do nosso grande e atabalhoado experimento em uma sociedade universalista que propõe um mundo sem nações onde qualquer um pode ser qualquer coisa, e o RG é planetário.

Não que você não deva prestar atenção à sua carteira, senhora (DOCTOROW, 2001, p. 
$11) \cdot{ }^{22}$

Com a invocação aparentemente emprestada ao enciclopedista chinês de Borges e com a adoção do princípio segundo o qual desarticulação ou disjunção se juntam à esperança, imagem e resposta utópicas, o catálogo de Doctorow multiplica, ad libitum, os jogos (a ruptura geral da linguagem a partir da constatação que as massas nos delineiam), em deslize e incerteza (o colapso da narrativa é entrevisto na afirmação que o começo das coisas depende da necessidade humana de caminhar entre estranhos), de coisas-dentro-de coisas (o confronto de pontos de vistas no movimento que segue a sobre-alma primacial, o RG planetário e a atenção à carteira), de listas-dentro-de listas (a fragilidade de valor e a vacuidade de sentido na poética do fenômeno, ou seja, o espetáculo do mundo não-natural e a atenção à carteira), que estão presentes de forma explícita, em maior ou menor grau, no espaço utópico-insólito das listas neste romance estadunidense da virada do século XXI.

Antes de concluir este artigo, sugiro que passemos os olhos por sobre a coleção insólita da protagonista da neozelandesa Keri Hulme, Kerewin, em seu romance The bone people:

A casca fina de cerâmica, torta, colorida de marrom e amarelo, manchada como uma mama infectada; taças de madeira esculpidas com hastes; as três bolhas puras de cristal, frágeis sobre as mais finas hastes possíveis; estanho emaranhado e opaco; prata gravada; um hemisfério claro de água-marinha, com falhas cintilando a luz daquele lado; a cuia de cristal lapidado e grosso que Charles, príncipe a muito tempo dos azarados e distantes Stuarts, deve ter possuído; vasilhas translúcidas de porcelana trazidas de volta do Japão; duas vasilhas de laca do tamanho de uma mão; uma taça de jade, onde cabe tanto vinho como numa casca de ovo, em um pedestal alto de marfim desgastado ... não há duas exatamente iguais. Tudo raro, tudo estranho ... especialmente aquela pequena e bizarra tigela de cerâmica que Simon usou em sua bebedeira (HULME, 1983, p. 335-336). ${ }^{23}$

$\mathrm{Na}$ sua casa-torre incomum, Kerewin salvaguarda sua coleção de objetos estranhos, onde tudo se dá a ver por meio de listas e inventários que fariam Eco, em The infinity of lists (2009), querer incorporar póstuma e virtualmente mais uma lista insólita, voraz e infinita, a seu livro. Vale lembrar que as listas, enquanto artifício retórico, têm seus inícios na antiguidade clássica e merece também ser rememorado o fato de que a lista acima sucintamente ventilada pertence à categoria das séries onde há uma coincidência entre o conteúdo das coisas elencadas, seu tema (o insólito, por exemplo), e o que venho discutindo com relação ao espaço liminar das listas em sua utopia (insólita) formal.

De uma maneira curiosa, e quiçá insólita, esta congérie de Hulme nos remete à lista do canadense Kroetsch e poderia se submeter a uma co-aparição, ou seja, um certo instante (comparatista) onde

22 No original: But I can stop on any corner at the intersection of two busy streets, and before me are thousands of lives headed in all four directions, uptown downtown east and west, on foot, on bikes, on in-line skates, in buses, strollers, cars, trucks, with the subway rumble underneath my feet ... and how can I not know I am momentarily part of the most spectacular phenomenon in the unnatural world? There is a specie recognition we will never acknowledge. A primatial over-soul. For all the wariness or indifference with which we negotiate our public spaces, we rely on the masses around us to delineate ourselves. The city may begin from a marketplace, a trading post, the confluence of waters, but it secretly depends on the human need to walk among strangers.

And so each of the passersby on this corner, every scruffy, oversize, undersize, weird, fat, or bony or limping or muttering or foreign-looking, or green-haired punk-strutting, threatening, crazy, angry, inconsolable person I see ... is a New Yorker, which is to say as native to this diaspora as I am, and part of our great sputtering experiment in a universalist society proposing a world without nations where anyone can be anything and the ID is planetary.

Not that you shouldn't watch your pocketbook, lady.

23 No original: A thin shell of pottery, lopsided, coloured brown and yellow, speckled like a thrush breast; wooden goblets with carved stems; the three pure bubbles of crystal, brittle upon the thinnest possible stalks; matt pewter; engraved silver; a clear hemisphere of aquamarine, flawed and scintillating with light on that one side; the thick, chunky cut glass that Charles, long ago prince of doomed distant Stuarts, was supposed to have owned; translucent bowls of porcelain brought back from Japan; two handsized lacquer bowls; a jade cup that held as much wine as an eggshell on a tall pedestal of fretted ivory ... no two quite the same. All rare, all strange ... especially that odd little pottery bowl that Simon used on his drinking spree. 
passamos a destituir o romance de sua condição de obra, acabada, de representação, para vê-lo como forma-força, como vetor apto a desequilibrar o arranjo de forças sempre tenso no espaço liminar dentro das e entre as listas literárias. No desejo de dar realidade a algo que é fugidio, que se esquiva da forma-força do realismo (formal), certos autores optam, de acordo com Wander Miranda em contexto diverso (Minas de Rosa, Drummond e Murilo Mendes), "pelo trabalho metonímico que resulta no empilhamento vocabular próprio do texto e que parece ironicamente assimilar, na sua feitura, a forma" (MIRANDA, 2002, p. 81), não mais das montanhas de Minas, mas de um mundo onde as temporalidades se multiplicam e as fronteiras são embaralhadas numa dispersão alucinante de pontos de fuga.

Por meio de acumulação e paradoxo, a poética da lista, nesses exemplos pelo menos, atinge o auge da ortodoxia e, ao mesmo tempo, confunde toda a ordem lógica pré-constituída ou realismo comum, enfatizando uma ruptura da linguagem, um colapso da narrativa, um confronto de pontos de vista subjetivos, a fragilidade do valor e a indefinição do sentido. Disjunção ou desarticulação das listas, ou o que venho chamando utopia (insólita) formal, não é apenas uma miscelânea de pedaços e fragmentos, percepções transitórias deste quebra-cabeça desagregado que é o nosso mundo contemporâneo, e também não é a mera celebração de um mosaico com peças que faltam ou se encontram ausentes, mas o conjunto de técnicas a partir do qual os romancistas anglófonos dos anos 70 ao início do século XXI começaram a representar o irrepresentável lado de uma visão mais particular e circunstancial da vida.

Em nota final, se o realismo formal tem a ver com uma técnica, uma forma ao invés de um conteúdo pontual, se o realismo formal, de acordo com Eagleton, insiste mais ardentemente sobre "a recalcitrância da realidade aos nossos desejos, a inércia obstinada com a qual a realidade desorienta nossos projetos, nossos desígnios" (EAGLETON, 2005, p. 4-5), ${ }^{24}$ eu finalmente proponho que a utopia (insólita) formal incidirá, por meio de listas, catálogos, inventários e enumerações sobre a subordinação da realidade aos nossos desejos, daí a ironia teimosa com a qual a realidade desorientará continuamente nossos projetos, nossos desígnios. Este tropo mestre, ironia, deve ser entendido por meio da posição de Hayden White em Metahistory, ou seja, a ironia "representa um estágio de consciência em que a natureza problemática da linguagem em si tornou-se reconhecida" (WHITE, 1973, p. 37). ${ }^{25}$ Para White, a ironia caracteriza a historiografia, mas ela pode muito bem se referir ao espaço liminar das listas e suas aparições insólitas em alguns romances em inglês ou ao que me refiro como sua utopia (insólita) formal. Mas devo acrescentar que, em nosso mundo contemporâneo, tal reconhecimento é explicitado nas vias de uma celebração. Em suma, esta empresa de fazer sentido, e é isso que os romances de forma geral são, por meio de suas listas, inventários e acumulações, é definitivamente um ato moral quando vista contra o pano de fundo de atos morais sempre dependentes da construção de sentido e é simultaneamente uma realização liminar e insólita quando vista contra o pano de fundo de aparições inabituais dependentes da possibilidade de criação de mundos mais-doque reais.

24 No original: The recalcitrance of reality to our desires, the sheer stubborn inertia with which it baffles our designs upon it.

25 No original: It represents a stage of consciousness in which the problematic nature of language itself has become recognized. 


\section{Referências:}

AUERBACH, Erich. Mimesis: the representation of reality in Western literature. Princeton: Princeton University Press, 1953 (2003).

COETZEE, J. M. Waiting for the barbarians. Nova Iorque: Penguin, 1982.

DOCTOROW, E. L. City of god. Nova Iorque: Plume, 2001.

EAGLETON, Terry. The English novel: an introduction. Oxford: Blackwell, 2005.

ECO, Umberto. The infinity of lists: from Homer to Joyce. Londres: MacLehose, 2009.

FOUCAULT, Michel. The order of things: an archaeology of the human sciences. Nova Iorque: Pantheon, 1970.

GREANEY, M. J. Contemporary fiction and the uses of theory: the novel from structuralism to postmodernism. Basingstoke: Palgrave, 2006.

HULME, Keri. The bone people. Londres: Penguin, 1983.

JAMES, Henry. The portrait of a lady. Nova Iorque: Penguin, 1986.

KROETSCH, Robert. The studhorse man. Toronto: Graham Law, 1970.

LUKÁCS, Georg. Theory of the novel. Cambridge: MIT Press, 1990.

MAZZONI, Guido. Theory of the novel. Trad. Zakiya Hanafi. Cambridge, Massachusetts: Harvard University Press, 2017.

MIRANDA, Wander Melo. Minas de Minas. In: Associação dos Amigos do Museu Mineiro (Org.). Colecionismo mineiro. Belo Horizonte: Secretaria de Estado da Cultura/Superintendência de Museus, 2002.

ROY, Arundhati. The god of small things. Londres: Flamingo, 1997.

WATT, Ian. The rise of the novel: studies in Defoe, Richardson and Fielding. Londres: Chatto \& Windus, 1957.

WHITE, Hayden. Metahistory: the historical imagination in nineteenth-century Europe. Baltimore: Johns Hopkins, 1973. 
